\title{
A comparative study to evaluate pregnancy related issues among women aged 35 years old and beyond
}

\author{
Heena Mir ${ }^{1 *}$, Neha Mahajan ${ }^{2}$ \\ ${ }^{1}$ Department of Health and Medical Education, Jammu, Jammu and Kashmir, India \\ ${ }^{2}$ Department of Obstetrics and Gynecology, GMC Jammu, Jammu and Kashmir, India
}

Received: 15 December 2021

Accepted: 30 December 2021

*Correspondence:

Dr. Heena Mir,

E-mail: heenaiqbalbhat84@gmail.com

Copyright: ( ) the author(s), publisher and licensee Medip Academy. This is an open-access article distributed under the terms of the Creative Commons Attribution Non-Commercial License, which permits unrestricted non-commercial use, distribution, and reproduction in any medium, provided the original work is properly cited.

\begin{abstract}
Background: The pregnancy complications associated with women over 35 years of age are becoming more frequent. Late or too late remains the thread bearing discussion these days. Multiple studies have reported that women with 35 years of age or beyond are more vulnerable to develop obstetric complications. The present study has been conducted to reckon the strength of the association between maternal age and obstetric issues pertaining to women.

Methods: This prospective study considered 217 single consecutive pregnancies which were divided into two groups based on age of patients. Group A consists of 163 pregnant women aged < 35 years and group B consists of 54 pregnant patients aged $\geq 35$ years. The study was conducted at government medical college, Lala-Ded, and hospital Srinagar.

Results: In spite of the underlying mechanisms, rigorous statistical analysis revealed the negative impact of extreme maternal ages on pregnancy. We found a significant difference between group A and group B with respect to early pregnancy loss, C-section, antepartum, intrapartum and postpartum complications $(\mathrm{p}<0.001)$.

Conclusions: Evidently, it was demonstrated that women aging 35 years or above are more vulnerable to develop multiple intrapartum and postpartum complications than younger women in group B.
\end{abstract}

Keywords: Antepartum complication, Ostpartum complication, Placenta previa, Assisted conception

\section{INTRODUCTION}

Maternal age has become all the more important factor to determine the severity of complications associated with pregnancy. However, there is no universal definition of advanced reproductive age in women, in part because the effects of increasing age occur as a continuum, rather than as a threshold effect. Fertility clearly declines with advancing age, especially after the mid-30s, and women who conceive are at greater risk of pregnancy complications. ${ }^{1}$ Even though there are multiple factors related to pregnancy outcome among women but age of women plays an important role in the conception process. Evidently advanced maternal age is largely correlated with inferior pregnancy outcomes among women because of higher incidence of some chronic medical conditions in older women. Developments in contraception and obstetric care as well as greater equality in the workplace have shifted the age distribution of the female population of reproductive age and influenced the timing of childbearing in these communities. There are multifaceted factors that encourage women to delay pregnancy process which includes financial goals, longer life expectancy, higher education, pursuit of career (Hansen 1986; and Bottoms, 1995) and sometimes due to miscalculations women halt the pregnancy process and subsequently invite major complications like; chromosomal abnormality, miscarriages, ectopic pregnancies and congenital anomalies, pre-eclampsia, gestational diabetes, intrauterine growth restriction and antepartum hemorrhage. ${ }^{2-5}$ There are some studies that have explored the association between maternal age and pregnancy outcome. Cesarean sections, instrumental assisted 
deliveries are more commonly adopted procedures among these women. ${ }^{6}$

\section{METHODS}

The present study was conducted in the Department of Obstetrics and Gynecoogy GNC Srinagar from February 2017 to August 2017. A total number of patients included in the study was 217 which were divided into two groups based on age of patients. Group A consists of 163 pregnant women aged < 35 years and group B consists of 54 pregnant patients aged $\geq 35$ years. Women who meet inclusion criteria and agreed to willfully participate in the study were evaluated for different parameters at outpatient department of obstetrics and gynecology. Routine antenatal examination along with some additional lab investigations like KFT; LFT etc. were performed. All women who qualified the inclusion criteria were asked for monthly follow-up till 28 weeks and then fortnightly follow was advised to these patients up to 36 weeks and thereafter weekly follow-up (unless some emergency issue) was recommended to them.

\section{Statistical methods}

The recorded data on various parameters like; assisted conception, early pregnancy loss, cesarean section, antepartum complications, intra and postpartum complications and NICU admission was compiled and entered in a spreadsheet (Microsoft excel) and then exported to data editor of SPSS Version 20.0 (SPSS Inc., Chicago, Illinois, USA). Statistical software SPSS (version 20.0) and Microsoft excel were used to carry out the statistical analysis of data. Continuous variables were expressed as Mean \pm SD and categorical variables were summarized as percentages. Chi-square test was employed for comparison of categorical variables. A $p<0.05$ was considered statistically significant. All $\mathrm{p}$ were 2 tailed.

\section{RESULTS}

In this section we will present the results of the study in tabular form.

Table 1: Comparison of various parameters.

\begin{tabular}{|c|c|c|c|c|c|}
\hline \multirow[t]{2}{*}{ Parameters } & \multicolumn{2}{|c|}{$\begin{array}{l}\text { Group A, } \\
(n=163)\end{array}$} & \multicolumn{2}{|c|}{$\begin{array}{l}\text { Group B, } \\
(n=54)\end{array}$} & \multirow[t]{2}{*}{$P$ value } \\
\hline & No. & $\%$ & No. & $\%$ & \\
\hline $\begin{array}{l}\text { Assisted } \\
\text { conception }\end{array}$ & 4 & 2.5 & 6 & 11.1 & $0.032 *$ \\
\hline $\begin{array}{l}\text { Early } \\
\text { pregnancy } \\
\text { loss }\end{array}$ & 10 & 6.1 & 9 & 16.7 & $<0.001 *$ \\
\hline $\begin{array}{l}\text { Cesarean } \\
\text { section }\end{array}$ & 56 & 34.4 & 21 & 38.9 & $0.018^{*}$ \\
\hline
\end{tabular}

Group A (Women <35 years); group B (Women $\geq 3$ years),

$*$ Statistically significant difference $(\mathrm{p}<0.05)$.
Table 1 , show that there were 163 women aged $<35$ years and 54 women aged $\geq 35$ years. The difference in number of cesarean sections, assisted pregnancies and early pregnancy loss between group A and group B was statistically significant. Evidently, out of 163 women in group A, (34.4\%) had cesarean section, (6.1\%) women had early pregnancy loss and $(2.5 \%)$ had assisted conception. On the other hand, in group B out of 54 patients, (38.9) patients had cesarean section, (16.7\%) had early pregnancy loss and (11.1\%) women had assisted conception.

Table 2: Comparison of antepartum, intrapartum and postpartum complications between the groups.

\begin{tabular}{|c|c|c|c|c|c|}
\hline \multirow[t]{2}{*}{ Parameters } & \multicolumn{2}{|c|}{$\begin{array}{l}\text { Group A, } \\
(n=163)\end{array}$} & \multicolumn{2}{|c|}{$\begin{array}{l}\text { Group B, } \\
(n=54)\end{array}$} & \multirow[t]{2}{*}{ P value } \\
\hline & No. & $\%$ & No. & $\%$ & \\
\hline \multicolumn{6}{|c|}{ Antepartum complications } \\
\hline $\begin{array}{l}\text { Hypertensive } \\
\text { disorder of } \\
\text { pregnancy }\end{array}$ & 12 & 7.4 & 11 & 20.4 & $0.007 *$ \\
\hline $\begin{array}{l}\text { Gestational } \\
\text { diabetes } \\
\text { mellitus }\end{array}$ & 11 & 6.7 & 5 & 9.3 & $0.002 *$ \\
\hline Placentia previa & 1 & 0.6 & 1 & 1.9 & $<0.001 *$ \\
\hline Preterm delivery & 19 & 11.7 & 13 & 24.1 & $0.011 *$ \\
\hline Induced labour & 17 & 10.4 & 5 & 9.3 & 0.805 \\
\hline \multicolumn{6}{|c|}{ Intrapartum and postpartum complications } \\
\hline Vaginal trauma & 6 & 3.7 & 5 & 9.3 & 0.105 \\
\hline $\begin{array}{l}\text { Postpartum } \\
\text { hemorrhage }\end{array}$ & 3 & 1.8 & 7 & 13.0 & $0.010^{*}$ \\
\hline
\end{tabular}

We observe that out of 163 women in group A, 56 had antepartum complications, of them $(11.7 \%)$ had preterm delivery, (10.4\%) had induced labour, (7.4\%) had hypertensive disorder of pregnancy, (6.7\%) had gestational diabetes mellitus and $(0.6 \%)$ had placenta previa. However, in B out of 54 women, 35 developed antepartum complications, of them (20.4\%) had hypertensive disorder of pregnancy, $(24.1 \%)$ had preterm delivery, (9.3\%) had induced labour, (9.3\%) had gestational diabetes mellitus and (1.9\%) developed placenta previa. Statistically, found both that both groups differ significantly from one another with respect to each and every antepartum, intra and postpartum complication except for induced labour and vaginal trauma.

Table 3: Comparison on NICU admissions in two groups.

\begin{tabular}{|c|c|c|c|c|c|}
\hline \multirow{2}{*}{$\begin{array}{l}\text { NICU } \\
\text { admission }\end{array}$} & \multicolumn{2}{|c|}{$\begin{array}{l}\text { Group A, } \\
(\mathrm{n}=\mathbf{1 6 3})\end{array}$} & \multicolumn{2}{|c|}{$\begin{array}{l}\text { Group B, } \\
(\mathrm{n}=54)\end{array}$} & \multirow{2}{*}{$\begin{array}{l}\mathbf{P} \\
\text { value }\end{array}$} \\
\hline & No. & $\%$ & No. & $\%$ & \\
\hline Yes & 17 & 10.4 & 8 & 14.8 & \multirow{3}{*}{0.382} \\
\hline No & 146 & 89.6 & 46 & 85.2 & \\
\hline Total & 163 & 100 & 54 & 100 & \\
\hline
\end{tabular}


We observe that both the groups are statistically comparable with respect to NICU admission with a $\mathrm{p}=0.382$, which means that the proportion of NICU admissions in both the groups is comparable.

\section{DISCUSSIONS}

In the present study on pregnancy in women aged 35 years and above; we thoroughly analyzed patients data based on: assisted conceptions, early pregnancy loss, cesarean sections, antepartum complications, intra, postpartum complications and NICU admission. Out of a total of 217 women patients, 163 were $<35$ years and 54 women were $\geq 35$ years. So, the classification of patients with respect to age threshold of 35 year was made. The patients were divided in two groups; group A consists of 163 women with age $<35$ years and group B consists of 54 women with age $\geq 35$ years. The difference in number of cesarean sections, assisted pregnancies and early pregnancy loss between group A and group B was statistically significant. Evidently, out of 163 women in group A, (34.4\%) had cesarean section, $(6.1 \%)$ women had early pregnancy loss and $(2.5 \%)$ had assisted conception. On the other hand, in group B out of 54 patients, (38.9) patients had cesarean section, (16.7\%) had early pregnancy loss and $(11.1 \%)$ women had assisted conception. Contemporary to the research, Pawde et al reported that women with 35 years of age and above had significantly higher rates of assisted conception $(12.6 \%)$ compared to $(3.5 \%)$ in women with $<35$ years old which in consonance to our observation, similarly they reported higher rates of early pregnancy $(18.9 \%)$ in women with 35 years of age and beyond compared to $(10.5 \%)$ in women with $<35$ years of age. ${ }^{7}$ Several authors have reported the similar kind of observations with regard to early pregnancy loses and assisted conceptions. ${ }^{7,8}$ We analyzed patients for antepartum intra and postpartum complications and observed that out of 163 women in group A, 56 had antepartum complications, of them $(11.7 \%)$ had preterm delivery, (10.4\%) had induced labour, (7.4\%) had hypertensive disorder of pregnancy, (6.7\%) had gestational diabetes mellitus and $(0.6 \%)$ had placenta previa. However, in group B out of 54 women, 35 developed antepartum complications, of them (20.4\%) had hypertensive disorder of pregnancy, $(24.1 \%)$ had preterm delivery, (9.3\%) had induced labour, (9.3\%) had gestational diabetes mellitus and (1.9\%) developed placenta previa. Statistically, we found both that both the groups differ significantly from one another with respect to each and every antepartum, intrapartum and postpartum complication except for induced labour and vaginal trauma. In tune with our observations, most of the authors have also reported higher incidence of hypertensive disorders in women aged 35 years and above. ${ }^{9,10}$ Pawde et al also reported significantly higher rates of hypertension $(17.54 \%)$, preterm delivery $(17.5 \%)$, gestational diabetes $(10.52 \%)$ in women aging 35 years or above compared to hypertension $(7.23 \%)$, preterm delivery (10.3\%), gestational diabetes $(6.43 \%)$ in women less than 35 years of age. ${ }^{7}$ However, Sahu et al reported $(10.1 \%)$ incidence of hypertensive disorders among pregnancy in older women while as Chibber et al and reported $(6.1 \%)$ of incidence of hypertensive disorders among older women. ${ }^{11,12}$ Similar to our observations, some authors have also reported significant difference between the two groups with respect to placenta previa, gestational diabetes. ${ }^{5,13}$ We observed a cesarean rate of $(34.4 \%)$ in group A compared to $(38.9 \%)$ in group B, however the difference was statistically insignificant. Contrary, to our observation reported significantly higher rates of cesarean sections for group B. ${ }^{14,15}$ In present study we found that the difference in number of intrapartum and postpartum complications is statistically significant in favor of group A. We observed that out of 163 women in group A, (3.7\%) had vaginal trauma and $(1.8 \%)$ had postpartum hemorrhage. However, in group B, out of 54 women, $(9.3 \%)$ had vaginal trauma and $(13 \%)$ had postpartum hemorrhage and the difference was significant with respect to postpartum hemorrhage but insignificant with respect to vaginal trauma. Labri et al have also reported a significant difference between the two groups with respect to vaginal trauma and postpartum hemorrhage. ${ }^{16}$ However, Pawde et al reported that $(5.26 \%)$ of women with 35 years of age and above had intrapartum complications compared to $(0.9 \%)$ in women with less than 35 years of age, reportedly there was a significant difference in intrapartum complications between the 2 groups, however, they found that both the groups are comparable with respect to postpartum complications. ${ }^{7}$ Finally, the comparison was made on the basis of neonatal outcome between the groups; we demonstrated both the groups are comparable with respect to number of admissions with a $p=0.122$. In consonance to our observations Pawde et al has also reported a similar result, they found an insignificant difference between the two groups with respect to NICU admissions. ${ }^{7}$ The reason for the insignificance between the groups with respect to NICU admission can be attributed to the management and timely intervention of health care workers.

\section{CONCLUSION}

The present study revealed that advanced maternal age is linked with disastrous pregnancy issues. Without any doubt, extreme maternal age invites a catastrophe of pregnancy related complications that include antenatal, intrapartum and postpartum complications. Natural conception becomes all the more challenging and hence the role assisted pregnancies comes into play. In order to minimize the late pregnancy issues the best way is to provide the evidence-based knowledge to women so that the procreate choices be optimized.

\section{ACKNOWLEDGMENTS}

Words fail to express our indebtedness and gratitude to Dr. Adil Rashid and Dr Zahoor Ahmad for their constant undaunted support in data analysis and other invaluable help, without them, this task could not have been accomplished. 
Funding: No funding sources

Conflict of interest: None declared

Ethical approval: The study was approved by the Institutional Ethics Committee

\section{REFERENCES}

1. Salihu HM, Shumpert MN, Slay M, Kirby RS, Alexander GR. Childbearing beyond maternal age 50 and fetal outcomes in the United States. Obstet Gynecol. 2003;102(5 Pt 1):1006-14.

2. Hansen JP. Older maternal age and pregnancy outcome: A review of the literature. Obstet Gynecol Surv. 1986;41:726-42.

3. Carolan MC. Towards understanding the concept of risk for pregnant women: some nursing and midwifery implications. J Clin Nurs. 2009;18(5):652-8.

4. Shimrit SY, Amalia 1, Arnon W. A significant linear association exists between advanced maternal age and adverse perinatal outcome. Arch Gynecol Obstet. 2011;283(4):755-9.

5. Yogev Y, Melamed N, Haroush B. Pregnancy outcome at extremely advanced maternal age. Am J Obstet Gynecol. 2010;203:558:e1-7.

6. Ales KL, Druzin ML, Santini DL. Impact of advanced maternal age on the outcome of pregnancy. Surg Gynecol Obstet. 1990;171:209-16.

7. Pawde Anuya A, Kulkarni Manjiri P, Jyothi U. Pregnancy in women aged 35 years and above: a prospective observational study. J Obstetr Gynecol India. 2015;65(2):93-6.

8. Leridon H. Can assisted reproductive technology compensate for the natural decline in fertility with age? A model assessment. Hum Reprod. 2004;19:1548-53.

9. Delbaere I, Verstraelen H, Goetgeluk S. Pregnancy outcome in primiparae of advanced maternal age. EJOG. 2007;135:41-6.

10. Jacobsson B, Ladfors L, Milsom I. Advanced maternal age and adverse perinatal outcome. Obstet Gynecol. 2004;104:727-33.

11. Sahu TM, Agarwal A, Das V. Advanced maternal age and obstetric outcome. J Obstet Gynecol India. 2007;57:320-3.

12. Chibber R. Problems of older maternal age and pregnancy outcome. Bahrain Med Bull. 2004;26:4.

13. Weerasekera DS, Udugama SG. Pregnancy outcome at 40 and over: a case control study in a developing country. J Obstet Gynecol. 2003;23:625-7.

14. Luke B, Brown MB. Elevated risk of pregnancy complications and adverse outcomes with increasing maternal age. Hum Repro. 2007;22:1264-72

15. Carloan MC, Davey M, Biro M. Very advanced maternal age and morbidity in Victoria, Australia: a population-based study. BMC Pregnancy Childbirth. 2013;13:80-9.

16. Larbi RKT, Buchmann EJ, Matshidze PR. Pregnancy outcome in urban black South African women aged 35 years and older. J Obstet Gynaecol. 2000;20:259-62.

Cite this article as: Mir H, Mahajan N. A comparative study to evaluate pregnancy related issues among women aged 35 years old and beyond. Int J Reprod Contracept Obstet Gynecol 2022;11:374-7. 